\title{
Influence of Accessibility on Land Use and Landscape Pattern Based on Mapping Knowledge Domains: Review and Implications
}

\author{
Yongwei Liu $\mathbb{D}^{1,2}$ Xiaoshu Cao, ${ }^{2,3}$ and Tao $\mathrm{Li}^{3}$ \\ ${ }^{1}$ School of Business, Ludong University, Yantai, Shandong, China \\ ${ }^{2}$ School of Geography Science and Planning, Sun Yat-sen University, Guangzhou, Guangdong, China \\ ${ }^{3}$ Institute of Transport Geography and Spatial Planning, Shaanxi Normal University, Xi'an, Shaanxi, China \\ Correspondence should be addressed to Yongwei Liu; 3629@ldu.edu.cn
}

Received 26 December 2019; Revised 13 May 2020; Accepted 20 May 2020; Published 18 July 2020

Academic Editor: Aboelmagd Noureldin

Copyright (C) 2020 Yongwei Liu et al. This is an open access article distributed under the Creative Commons Attribution License, which permits unrestricted use, distribution, and reproduction in any medium, provided the original work is properly cited.

Research on the influence of accessibility on land use and landscape patterns is one of the most important subfields in landscape ecology and transportation geography. In this review article, we use CiteSpace and VOSviewer to analyze relevant information, including the number of published papers, highly cited literature, high-frequency keywords, periodicals, and the leading countries conducting research on this particular field. Based on the mapping knowledge domain theory and summarizing method, this research, using an extensive review of the existing literature to analyze the influence of accessibility on land use and landscape patterns, the following conclusions have been reached: first, most of the relevant studies are conducted by applying theories on landscape ecology rather than on transportation geography, and the measure index of accessibility is relatively simple. Second, while accessibility has played a key role in analyzing the interactions between transportation, land use, and landscape patterns, studies on the long-term effect of transportation on land use and land patterns are extremely important. Also, different road types have been found to impose different effects. Third, research on the functional landscape in inner cities has become a significant research focus, particularly with the progress in big data. And fourth, improvements in data acquisition and processing have greatly benefited the field, specifically with recent advancements in GIS and RS technology. However, studies on landscape patterns with regional perspectives have largely been insufficient, especially those conducted over long time scales.

\section{Introduction}

By the definition by Troll [1] in 1939, landscape ecology is a highly interdisciplinary subject that includes ecology, geographical science, and environmental sciences. It focuses on the question of how to understand and improve the relationship between spatial patterns and ecological processes in multiple scales [2]. One of its subfields is road ecology, which has gradually advanced since its introduction in the 1970s. With increasing attention in research and scientific discussions on road ecological effects in various countries, more and more literature studies have been published since the 1990s. The book, Road Ecology: Science and Solution [3], written by Forman and 14 other scientists in 2003, claims that road ecology research has entered a stage of rapid development. Underlying assumptions on the impact of transportation infrastructure in the landscape structure and processes have been clearly demonstrated in a number of European countries, where the development of transportation infrastructure has been accompanied by landscape fragmentation [4-6]. Likewise, American studies have also played a critical role in the progress of transportation infrastructure [7-10].

The role of transportation infrastructure development has become more and more important and focused on a variety of topics, such as the road structure [11-13] and on the influence and effects of road construction [14, 15]. Given the crucial role of transportation infrastructure construction in landscape patterns in the study of road ecology, accessibility (also known as transportation accessibility or traffic accessibility) is regarded as a crucial indicator in analyzing transportation effects. Studies regarding its influence on 
landscape patterns have become common in the fields of transportation geography and landscape ecology. Accessibility, first put forward by Hansen, is defined as the possibility of interaction among different factors in the transportation network [16]. In recent years, more and more studies have focused on exploring the influence of transportation infrastructure construction. At present, conducting research in different time periods and region types has become ubiquitous, given that historical data have become easier to obtain, and analysis has significantly improved with the use of GIS and RS technology. The number of research studies on landscape patterns, conducted over long periods and in studying various aspects and different region types, has been increasing. Landscape patterns can be used to study not only land-use types and their spatial distribution features but also various land types in entire regions or intraregions. Thus, analyzing the influence of accessibility on the landscape pattern is essential to provide guidance for regional transportation infrastructure construction and economic and social development.

This article used CiteSpace [17] and VOSviewer in reviewing relevant studies on the influence of accessibility on land use and landscape patterns from the database of Web of Science. The main objective of this paper is to get an understanding of the basic knowledge, the latest research achievements, and the most popular research subjects.

\section{Analysis Based on Mapping Knowledge Domains}

2.1. Data Source. Relevant literature data collected from the Web of Science were reviewed using search keywords "accessibility OR road OR traffic OR transport OR transportation" and "land use OR landuse OR landscape" and had been collected before March 2019. Since the research focus is on land use and landscape patterns, studies on flora and fauna, hydrology, and geomorphology had been excluded. Statistical data show that 286 papers [18-38] have been published (among the articles, a detailed list of the literature is in Supplementary Materials). Many of the articles were published after 2000, particularly in the year 2003. The number of articles proliferated from 2003 to 2018, which showed an increase from 6 to 40. In analyzing highly cited articles in Table 1, the role articles plays in searches would be clearly apparent. Research content is relatively inclusive, focusing mainly on issues such as disciplinary system, landscape changes, and its influencing factors on urbanization.

2.2. Analysis of Research Focus. The content of a paper can be generally reflected by the keywords, while the research focus is usually reflected by the frequency of keywords used. As shown in Table 2 and Figure 1, "land-use change," "pattern," and "urbanization" have been frequently used as keywords. They also have high betweenness centrality, indicating the research studies on urbanization, land-use changes, and land-use patterns have become increasingly popular. Keywords such as "land-use changes," "patterns," "dynamics," "fragmentation," and "deforestation" with relatively high centrality have been used before 2003, indicating that these keywords have always been a research focus. The keywords "urbanization," "growth," "China," "model," and "landscape pattern" also show high centrality, demonstrating that research studies on such fields have been increasing. Keywords, such as "driving force," "impact," "spatial-temporal patterns," "spatial-temporal analysis," and "spatial regression" appear around 2010, showing that recent studies have been inclined to focus on spatial and temporal aspects, particularly on driving force and impact.

As shown in Table 3, periodicals on landscape, land, and ecology, such as Landscape and Urban Planning and Landscape Ecology, are highly cited with high centrality. In contrast, periodicals related to transportation hardly hit the Top 20, except for the Journal of Transport Geography. This means landscape, land, and ecology are frequently and extensively studied subfields, while transportation has not been as popular. Table 3 also shows that the number of cocitations in the journal Science reached 63, showing that the research has a broad understanding of the academic frontier.

As shown in Figures 2 and 3, the United States and China are the two leading countries. While China started research on the field later than the United States and the Netherlands, the number of studies and the influence coming from Chinese scholars have increased significantly. Most of the cocitation literature focus on the driving factors of urban growth, as well as the relationship between transportation infrastructure and landscape change.

\section{Results}

3.1. Influence of Road Construction on the Surrounding Areas. One research subfield focuses on the influence of roads and railways on land use and landscape pattern of the surrounding areas. Many studies take the road-effect zone as the key research area, and relatively less have focused on the influence of railways on the surrounding areas. There are a number of contradictions among the research results. For example, $\mathrm{Wu}$ and Yeh found that the distance from railway lines does not affect land-use changes when analyzing related research data in Guangzhou in 1979-1992 [50]. After analyzing data from Nanjing, Luo and Wei argued that railway construction would prevent the conversion of land into urban land, suggesting that railways are used not to promote inner-city development but to strengthen links among different cities [51]. Xie and Levinson posited railway has a significant role in promoting residential development, as shown in their research on Minneapolis and St. Paul (data collected from 1900-1930) [52]. Deng et al. found that expressway construction can improve land-use efficiency [53]. Their study on the influence of expressways on cultivated land in Shandong province shows that expressway construction has a positive impact on increasing the area of the cultivated land in areas with relatively high population density. Muller et al. found that areas close to the road network are more likely to see substantial changes in land use or land cover, mainly affecting the conversion of 
TABLE 1: Statistics on highly cited articles (TOP10).

\begin{tabular}{|c|c|c|c|c|}
\hline Author & Articles & $\begin{array}{l}\text { Publication } \\
\text { year }\end{array}$ & Periodical & $\begin{array}{l}\text { Citation } \\
\text { frequency }\end{array}$ \\
\hline Antrop & Landscape change and the urbanization process in Europe [39] & 2004 & $\begin{array}{l}\text { Landscape and Urban } \\
\text { Planning }\end{array}$ & 591 \\
\hline Antrop & Why landscapes of the past are important for the future [40] & 2005 & $\begin{array}{l}\text { Landscape and Urban } \\
\text { Planning }\end{array}$ & 564 \\
\hline Luck and $\mathrm{Wu}$ & $\begin{array}{l}\text { A gradient analysis of urban landscape pattern: a case study from } \\
\text { the Phoenix metropolitan region, Arizona, USA [41] }\end{array}$ & 2002 & Landscape Ecology & 424 \\
\hline Bürgi et al. & Driving forces of landscape change-current and new directions & 2004 & Landscape Ecology & 337 \\
\hline Forman & $\begin{array}{l}\text { Estimate of the area affected ecologically by the road system in the } \\
\text { United States [43] }\end{array}$ & 2000 & Conservation Biology & 335 \\
\hline Coffin & $\begin{array}{l}\text { From roadkill to road ecology: A review of the ecological effects of } \\
\text { roads [44] }\end{array}$ & 2007 & $\begin{array}{l}\text { Journal of Transport } \\
\text { Geography }\end{array}$ & 334 \\
\hline Serra et al. & $\begin{array}{c}\text { Land-cover and land-use change in a Mediterranean landscape: A } \\
\text { spatial analysis of driving forces integrating biophysical and } \\
\text { human factors [45] }\end{array}$ & 2008 & Applied Geography & 286 \\
\hline $\begin{array}{l}\text { Forman and } \\
\text { Deblinger }\end{array}$ & $\begin{array}{c}\text { The ecological road-effect zone of a Massachusetts (USA) } \\
\text { suburban highway [46] }\end{array}$ & 2000 & Conservation Biology & 273 \\
\hline Wu and David & $\begin{array}{l}\text { A spatially explicit hierarchical approach to modeling complex } \\
\text { ecological systems: theory and applications [47] }\end{array}$ & 2002 & Ecological Modelling & 256 \\
\hline Deng et al. & $\begin{array}{c}\text { Growth, population and industrialization, and urban land } \\
\text { expansion of China [48] }\end{array}$ & 2008 & $\begin{array}{l}\text { Journal of Urban } \\
\text { Economics }\end{array}$ & 235 \\
\hline
\end{tabular}

nonurban land into urban one (e.g., urbanization). Their study conducted in Switzerland using data from 1985 to 1997 also demonstrated that proximity (being measured as the distance from a motorway exit) to motorway aids in hastened urbanization [54]. Conway, based on his research conducted in New Jersey (1986-1995), concluded that accessibility to urban or employment centers is correlated with the development of emerging cities [55]. However, several studies have noticed differences in the influence of road network development on land-use changes mainly due to the effect of location. Mothorpe et al. believed that land-use changes are closely linked with the initial level of urbanization. They argued that among urban, rural, and suburban regions, only urban areas would see significant expansion of urban land as the road network develops [56] and that road construction curbs residential development [57].

Since lands near to roads are more inclined to be affected by natural, economic, and social impacts from road construction, they would be more likely to become fragmented and isolated, causing more changes in land use and landscape patterns when compared to peripheral areas. Forman and Deblinger believed that the road-effect zone is important in assessing road systems. They argued that the biophysical system shows different spatial mode characteristics on both sides of the road since the road-effect zone, which develops by the directed flow, is typically asymmetric [46]. There have been numerous studies focused on the road-effect zone. Forman and Alexander had estimated that the road-effect zone in America accounts for $15-20 \%$ of the total land area, which is 19 times the area of the road network itself [58]. Reijnen et al. found that $16 \%$ area of the Netherlands is located in the road-effect zone [59]. Wu et al. showed that the road-effect zone of Highway 6 construction extends $400 \mathrm{~m}$ perpendicular to the length of the highway [60]. Hu and Lo found that, in Atlanta, the probability of urban development in areas close to a major highway is nearly twice than in areas one kilometer away from the road [61].

3.2. Influence of Road Network Characteristics. Road network characteristics have become common indicators about the influence of accessibility on land use and landscape patterns. This is because road networks exert influence on the ecosystem and landscape patterns when land-use types change. Usually, research on road network characteristics is quantitative and involves the use of the landscape pattern index. Road density has become the most important indicator used in relevant studies, but its interaction mechanism tends to be somewhat complicated. Hawbaker et al. analyzed the relationship between land-use type and road density in Wisconsin and found that the influence of road density on landscape changes is different among various land-use types [62]. Luo et al. used effective mesh size to study landscape fragmentation alongside road networks in Fujian, China, to explore the influence of socioeconomic processes, such as urbanization and industrialization, on landscape changes [63].

Kernel density estimation (KDE) has become an important research technique since it can overcome limitations of traditional methods when calculating road density in underlying administrative boundaries. For instance, in a study using KDE, Cai et al. found that areas with higher road density tend to have more construction lands and less forest lands. Their study demonstrated that KDE would be very effective in studies on road fragmentation and landscape fragmentation [64]. Likewise, the use of complex network theories has emerged, particularly in studies analyzing the correlation between different network indexes and 
TABLE 2: Statistics on high-frequency keywords.

\begin{tabular}{|c|c|c|c|}
\hline Keywords & Frequency & Centrality $^{a}$ & Year \\
\hline land use change & 61 & 0.18 & 2003 \\
\hline pattern & 52 & 0.17 & 2000 \\
\hline urbanization & 47 & 0.12 & 2004 \\
\hline driving force & 41 & 0.08 & 2009 \\
\hline china & 40 & 0.12 & 2008 \\
\hline land use & 37 & 0.1 & 2006 \\
\hline city & 37 & 0.06 & 2003 \\
\hline growth & 35 & 0.16 & 2006 \\
\hline dynamics & 34 & 0.06 & 2002 \\
\hline gi & 31 & 0.16 & 2004 \\
\hline impact & 29 & 0.05 & 2009 \\
\hline model & 29 & 0.12 & 2004 \\
\hline fragmentation & 26 & 0.1 & 2002 \\
\hline expansion & 24 & 0.05 & 2013 \\
\hline region & 24 & 0.04 & 2007 \\
\hline landscape & 23 & 0.03 & 2005 \\
\hline cover change & 23 & 0.04 & 2004 \\
\hline accessibility & 22 & 0.03 & 2005 \\
\hline road & 21 & 0.07 & 2007 \\
\hline urban growth & 21 & 0.06 & 2013 \\
\hline logistic regression & 20 & 0.02 & 2007 \\
\hline deforestation & 20 & 0.17 & 2000 \\
\hline landscape pattern & 18 & 0.07 & 2004 \\
\hline area & 16 & 0.05 & 2009 \\
\hline land cover change & 13 & 0.02 & 2007 \\
\hline cellular automata & 12 & 0.03 & 2016 \\
\hline urban expansion & 12 & 0.04 & 2016 \\
\hline transportation & 12 & 0.04 & 2013 \\
\hline conservation & 12 & 0.11 & 2007 \\
\hline landscape metrics & 12 & 0.01 & 2006 \\
\hline united states & 11 & 0.06 & 2005 \\
\hline landscape change & 11 & 0.01 & 2005 \\
\hline remote sensing & 11 & 0 & 2013 \\
\hline biodiversity & 10 & 0.02 & 2014 \\
\hline density & 9 & 0.06 & 2000 \\
\hline scale & 9 & 0.02 & 2002 \\
\hline determinant & 9 & 0.07 & 2016 \\
\hline ecology & 8 & 0.01 & 2014 \\
\hline metropolitan area & 8 & 0 & 2015 \\
\hline management & 8 & 0.04 & 2013 \\
\hline
\end{tabular}

${ }^{a}$ Betweenness centrality of a node, which captures the number of times the node is included in the shortest paths of any pair of nodes in the keyword network. The larger the value of betweenness centrality, the higher the influence of one specific keyword [49].

landscape pattern indexes. For example, Liu and Dong found that the expansion of road networks can intensify landscape pattern fragmentation. Conducted in the county of Lancang River Basin, their study analyzed graphs of theoretical indexes describing network features and landscape patterns [65].

\subsection{Influence of Different Road Types and Their Cumulative} Effects. The influence of different road types (e.g., rural roads, railways, and highways) on land use and landscape pattern may vary but is undoubtedly significant. In a study from Western Europe, Pauwels and Gulinck concluded that rural roads could change agricultural landscapes significantly when the rural functional landscape of the road-verge network changes [66]. Nogues and Cabarga-Varona posited that highway construction is a crucial factor affecting landscape connectivity [67]. Liu et al. found that low-level roads have a relatively considerable impact on vegetation and that minor roads, including types IV and V roads, have the greatest impact on regional landscape fragmentation [68]. Su et al. found that different road types, such as railways, highways, national roads, and provincial roads, have a significant effect on landscape diversity, and the impact of railway is more significant than provincial roads [69].

The influence of road construction on landscape fragmentation has become a major research focal point. It is usually analyzed by calculating the landscape pattern index of road networks in different land-use types. For example, by applying an effective mesh size method, Li et al. found that there are significant differences in landscape fragmentation, which is affected by highways and railways [70]. Their study, which was conducted in China, also found that such influence is least evident in the country's western region and strongest in China's southern and eastern regions. PatruStupariu et al. studied the Carpathian Mountains in southern Romania and verified their assumption about landscape fragmentation by calculating the effective mesh size from the EEA report [71].

\subsection{Influence from Different Perspectives}

3.4.1. Research Studies on Urban Areas Focus on Construction Land. The influence of distance accessibility on urban expansion has become an important part of the current research trend. Transportation infrastructure has played a positive role in urban development. If land accessibility could be improved to provide more roads for people and goods, economic development could further advance. Thus, transportation infrastructure has been regarded as a major factor in advancing urban development [72]. Road construction has also been shown to have a direct impact on the direction and degree of urban growth. In Istanbul, Ayazli et al. estimated that a third bridge would exert substantial influence on a region, which would lead to $41 \%$ of forested areas and $28 \%$ of fragile ecosystem areas be transformed into urban areas by 2030 [73]. Although expansion could be affected by numerous factors, such as economic development and social processes, its relationship with transportation infrastructure construction has been well documented. In Jeddah, Saudi Arabia, Aljoufie et al. showed that, in the past 40 years, transportation infrastructure had developed alongside land-use changes, highlighting the relationship between urban growth and transportation infrastructure in rapidly urbanizing areas [74]. Wang and $\mathrm{Lu}$ selected 55 mountain cities to explore the driving factors of construction land expansion in China from 1990 to 2015 and found road construction, GDP, and population growth as major driving mechanisms [75]. Li et al. evaluated the changes in the construction land area and proportion to analyze driving factors of urban expansion in Beijing. Their study concluded that economy is the most vital factor in 


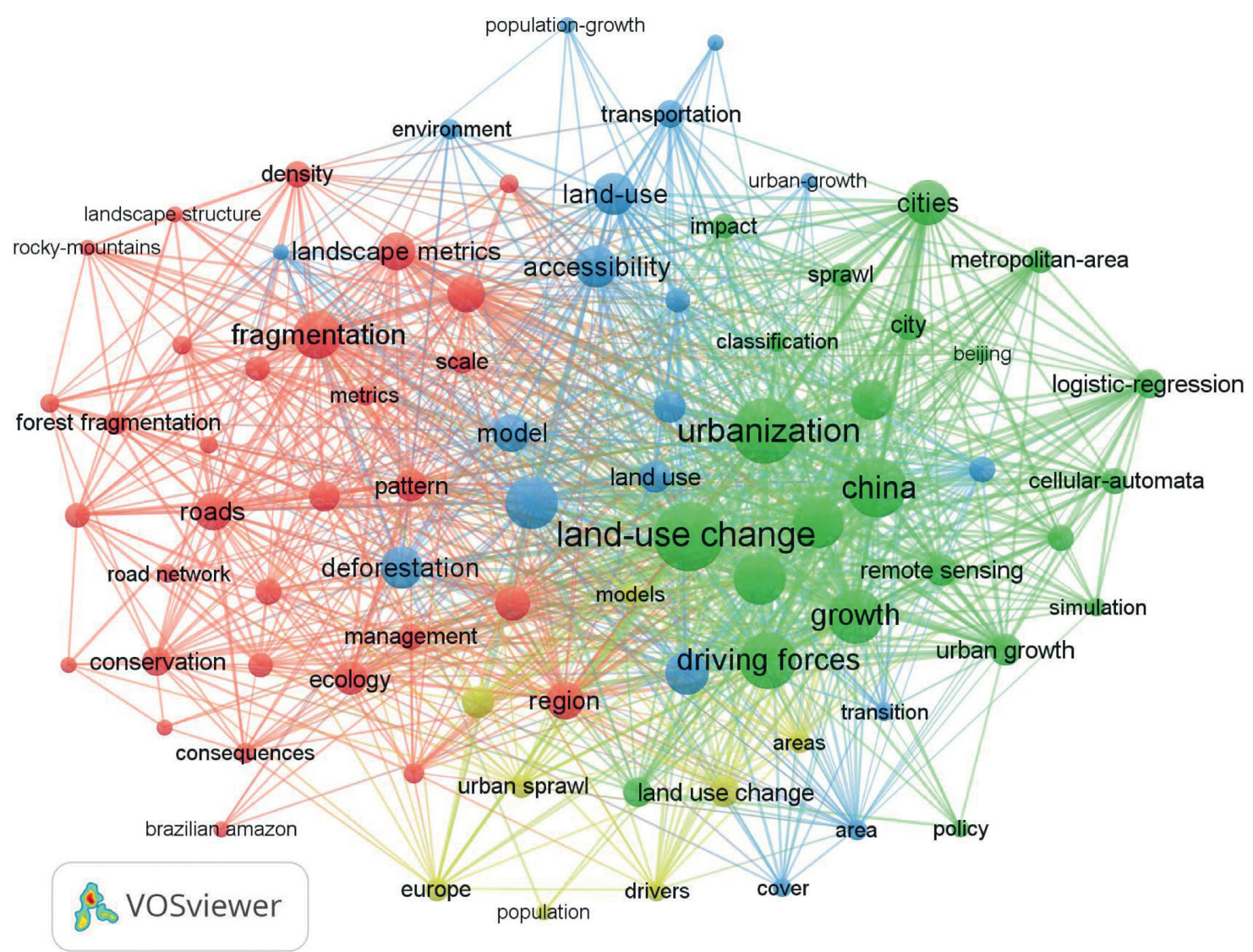

FiguRE 1: Keywords' co-occurrence network. The node represents a keyword, the size of the node indicates the number of occurrences, and the line thickness of the two nodes represents the degree of connection.

TABLE 3: Statistical on journal cocitation.

\begin{tabular}{|c|c|c|c|}
\hline Name & Frequency & Centrality & Year \\
\hline Landscape and Urban Planning & 173 & 0.06 & 2002 \\
\hline Landscape Ecology & 154 & 0.11 & 2000 \\
\hline Land Use Policy & 110 & 0.06 & 2006 \\
\hline Applied Geography & 99 & 0.02 & 2006 \\
\hline Journal of Environmental Management & 88 & 0.06 & 2006 \\
\hline Agriculture Ecosystems \& Environment & 81 & 0.03 & 2004 \\
\hline Biological Conservation & 74 & 0.08 & 2000 \\
\hline Environmental Management & 74 & 0.07 & 2000 \\
\hline Urban Studies & 71 & 0.04 & 2003 \\
\hline Ecological Modelling & 69 & 0.09 & 2005 \\
\hline Conservation Biology & 65 & 0.06 & 2000 \\
\hline International Journal of Geographical Information Science & 65 & 0.04 & 2004 \\
\hline Journal of Transport Geography & 64 & 0.19 & 2007 \\
\hline Science & 63 & 0.15 & 2002 \\
\hline Remote Sensing of Environment & 63 & 0.06 & 2006 \\
\hline Environment and Planning B: Planning and Design & 62 & 0.04 & 2004 \\
\hline Environment and Planning A: Economy and Space & 61 & 0.11 & 2003 \\
\hline International Journal of Applied Earth Observation and Geoinformation & 60 & 0.02 & 2011 \\
\hline Cities & 57 & 0.02 & 2009 \\
\hline Global Environmental Change: Human and Policy Dimensions & 56 & 0.06 & 2004 \\
\hline
\end{tabular}

affecting expansion, while factors like the natural environment and geographical proximity, have seen a reduction in their impact on expansion [76]. More and more methods, such as the grid and geodetector methods, have continued to develop, which could be used in this field of study. Using the grid method, Zhang et al. found that accessibility has a significant impact on urban landscapes [77]. Their results also showed that the distance from national or provincial 


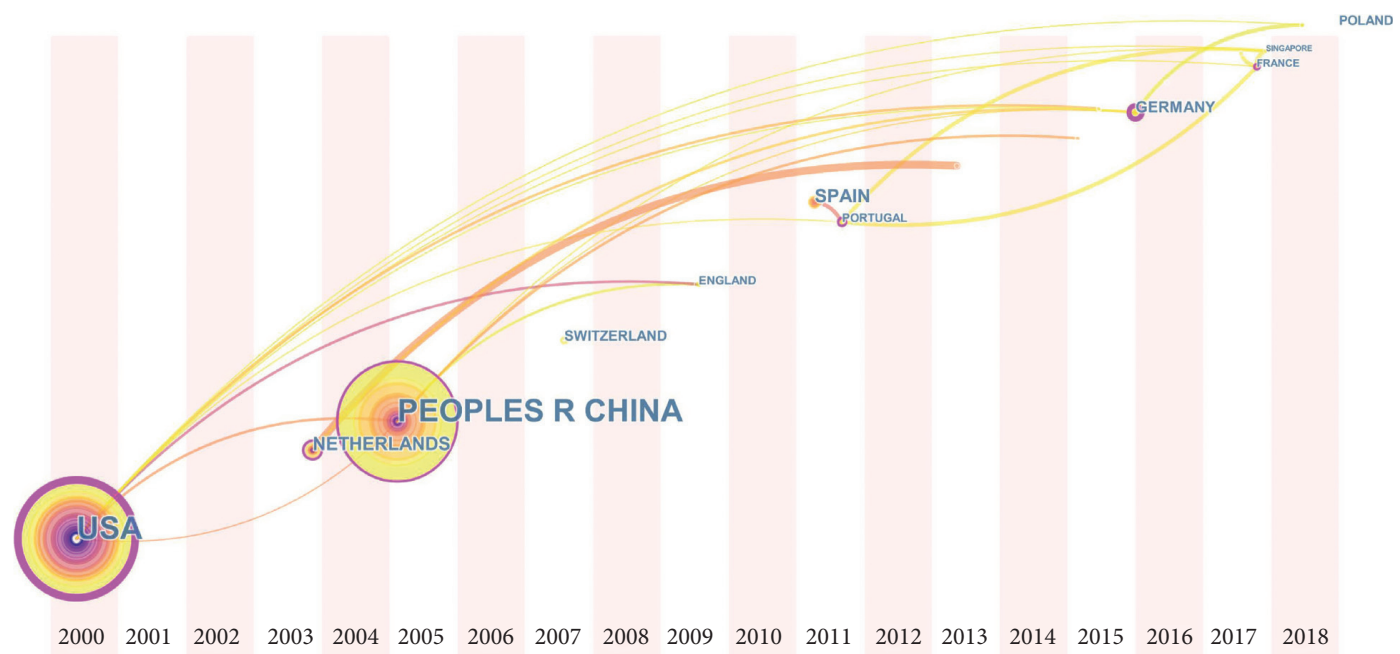

Figure 2: Timeline view on country cooperation.

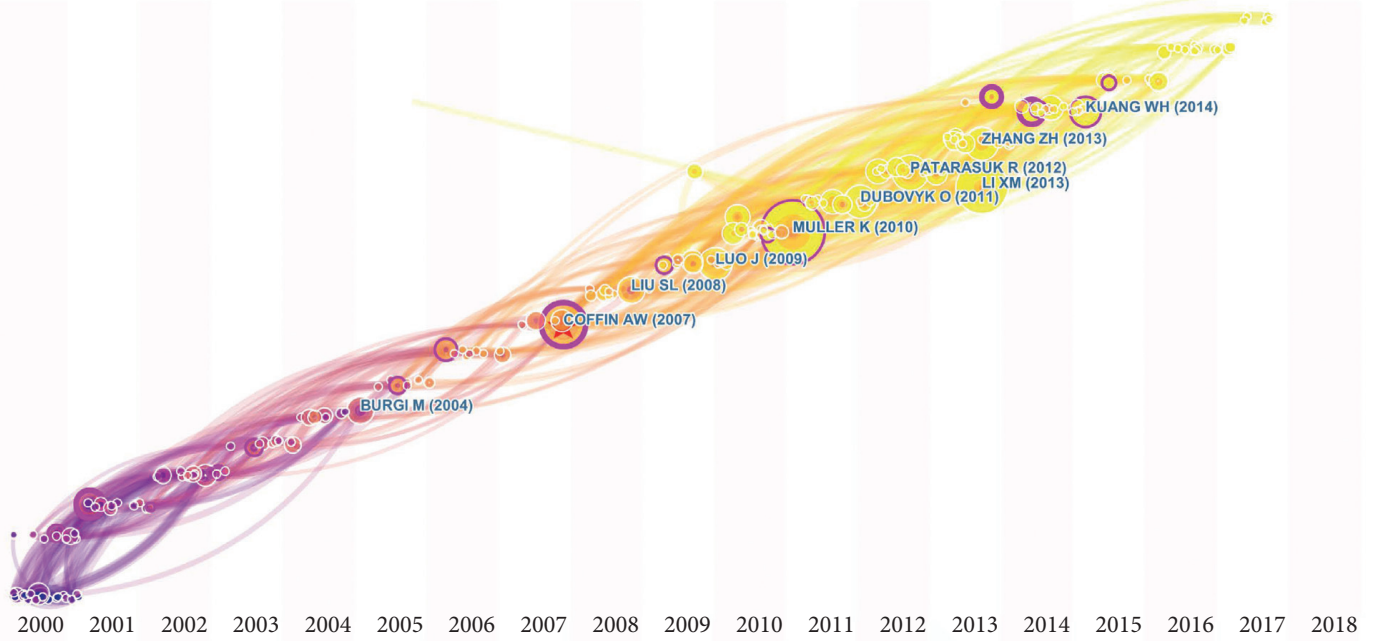

FIgURE 3: Timeline view on literature cocitation.

roads affects the change of the urban model and that the influence of city centers on expansion is weakened with continued urban growth. Ju et al. used the geodetector method to explore the influence of different single and combined factors on built-up land expansion. Their results showed that combined factors contribute more to expansion than single factors, providing a new perspective in exploring interactions among various influencing factors [78].

As in the interior of the city, there are variations in the influence of different land-use types on roads, and there is no singular, unified relationship model. Wu and David posited that the urban land structure has a certain feature wherein different land-use types develop landscapes and landscape-form areas, indicating a hierarchical structure in the ecosystem [47]. Lin et al. introduced the concept of urban functional landscape, suggesting that there are significant differences among spatial pattern distributions in various functional zones along an urban-rural gradient [79].
3.4.2. Research Studies on Rural Areas Focus on Farming Land and Forest Land. Studies in rural areas consider the characteristics of the region and mainly focus on the study of characteristic landscapes, including forest landscape, farming landscape, and mountain landscape. Eker and Coban believed that roads in forest areas have many influences on landscapes, and their influence on the spatial structure of the forest landscape is significant [80]. Zhao et al. studied artificial forest areas in Ximeng County in Yunnan province and found that accessibility plays a vital role in affecting land-use changes [81]. McGarigal et al. investigated landscape changes affected by road construction and logging activity in the southern part of the North American Rockies. Their findings showed that the cumulative effect caused by the landscape could be negligible within ten years, but the effect would be noticeable within 40 years [82]. Freitas et al. conducted a case study in São Paulo and found that forest landscape fragmentation is influenced by topographic conditions, land use, and road density [83]. 
The influence of road construction on the surrounding forest landscapes is analyzed mainly by examining the influence on habitats and ecological flows. The accessibility measures range from simple distance measures to land-use type specific transport costs and a population potential measure, Verburg et al. suggested that the relationship between accessibility and land use is interrelated with the characteristics of different land-use types [84]. Shaw found that changes in the transportation system could change accessibility and affect land use, which could consequently affect trip activities and trip modes, thereby further changing the transportation system [85]. In terms of accessibility in rural areas, Castella et al. found that the location of villages has a strong correlation with road networks and land-use systems and is related to its poverty level and its development potential [86]. Nagendra et al. argued that deforestation and fragmentation are more apparent in areas with high accessibility, but the levels may differ due to varying time scales [87]. Berg et al. studied the relationship between access to markets and cultivated lands in sub-Saharan Africa and found a positive association between increased market accessibility and local cropland expansion [88].

3.4.3. Research on the Overall Region Is Conducted from Urban Areas to Rural Areas. Comprehensive studies that include both urban and rural areas could demonstrate spatial distribution features of the landscape pattern and distribution differences between cities, suburbs, and villages. They could be used to analyze areas between urban and rural zones and the impact of road proximity, which has been considered in many studies, on land use and landscape pattern. This approach is called urban-rural gradients, which had been introduced by McDonnell and Pickett [89], and is now widely applied in detecting landscape patterns [41] and change from the urban to the rural [90]. Regarding special urban-rural gradients, changes in landscape patterns and variations in different districts (e.g., city, suburban, and village) could be analyzed systematically, highlighting distinct differences between urban and rural areas. In Tallinn, Estonia, Reimets et al. selected three major roads to evaluate landscape pattern changes and concluded that landscape fragmentation decreases with increasing distance from roads [91]. They also found that fragmentation due to the distance from the city center is less severe than the distal effects from roads. Zhu et al. analyzed the influence of road corridors on landscape patterns with the perspective of the urban-rural gradient, pointing out landscape density has a significant correlation with road coverage [92]. Antrop believed that the difference in accessibility between urban and rural areas is an important factor affecting landscape changes and urbanization and that transportation infrastructure is a major cause of the disparity [39]. There is a casual relationship between transportation infrastructure and land-use change, but the relationship may vary for different infrastructures. In Qixia district of Nanjing, Zhang et al. studied a typical urban-rural fringe area and found that construction lands tend to be close to the main roads and that the impact of different transportation infrastructures on land-use varies [93]. Their results showed that railways have considerable influence on land-use change, while roads with less traffic flow are not as significant.

The number of comprehensive research studies studying whole regions has been limited, especially those that study urban agglomeration in economically developed regions. Studies conducted over long time periods have also been minimal. Brinkmann et al. evaluated the relationship between land-use change and landscape transformation process, focusing on the forest landscape, agricultural landscape, construction landscape, and abandoned landscape. Conducted in West African cities and surrounding areas, their study provided a system analysis on land-use change, driven by agricultural and ecological infrastructure construction, and processes, including urbanization, agricultural production increase, land abandonment, and deforestation, that have occurred over the past 50 years [94]. Watts et al. introduced the roadless volume (RV), which is the calculated distance of an object to the nearest road [95]. Fu et al. used the RV to analyze the disturbance effect of road networks and concluded that road networks generally transform the landscape pattern from forests and croplands into large patches of urban lands surrounding roads [96].

\section{Influence Mechanism}

The influence mechanism of accessibility on land use and landscape pattern is affected by many factors, such as sociodemographic factors, economic and cultural factors, regional demand, land availability, and spatial policy. Although the influence mechanism is complex, it still has some regularity.

As a more informative and revealing representation of land use, landscape patterns reflect the composition of different land-use types and their spatial distribution. The landscape pattern can not only research the characteristics of the whole region but also research the characteristics of different land-use types in the region. For the entire study area, different land-use types, such as construction land, cultivated land, and forest land, could be studied. Further analysis of landscape patterns could be done to study patch development, patch types, and landscape development. In 1959, Hansen proposed the concept of accessibility and studied the relationship between accessibility and land use in urban areas by applying the gravity model [16]. This means that, at the early stages of conception, accessibility has been closely linked to the interactions between transportation, land use, and landscape patterns [97]. Over time, road construction has been shown to effectively influence landscape changes [63]. The theoretical framework on the influence of accessibility on land use and landscape pattern has been developed based on the studies by Kasraian et al. [97-99]. The framework is shown in Figure 4.

On the one hand, the development of transportation can improve accessibility level, which in turn promotes demand for more development in urban areas. On the other hand, land urbanization can advance transportation expansion and increase the demand for diversity in transportation. 


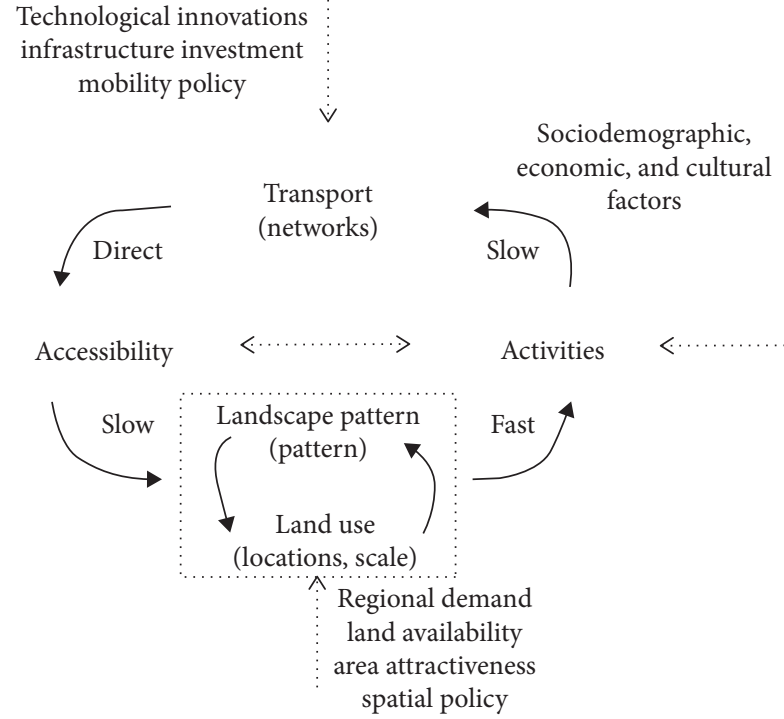

FIGURE 4: Influence mechanism of accessibility on land use and landscape pattern [97-99].

The interaction between accessibility and land use is direct and relatively fast, and also a long-term and dynamic system [100]. External factors, such as new technology, economic growth policy, transportation management, and sustainable goal, play significant roles in affecting transportation networks, while land-use accessibility, regional attractiveness, regional economic power, and spatial policy exert influence on land use and landscape patterns. While accessibility is the most important factor affecting landscape pattern changes, other accessibility indicators have to be considered, such as travel time and travel cost, when studying the influence of the landscape pattern from the perspective of distance variables [97-99].

\section{Conclusion and Implications}

\subsection{Conclusion}

(1) Using CiteSpace and VOSviewer, we found that much of the studies have been published after 2003, with the number of published articles increasing from 6 in 2003 to 40 in 2018. Also, most of the studies have mainly focused on combining the disciplinary system, landscape changes and their influencing factors, and empirical research related to urbanization.

(2) Through an assessment of keywords, journals, literature, and national cooperation networks, we found that recent studies have focused on the spatial and temporal aspects, particularly on the driving forces and their impact. Most important papers are published in journals dealing with landscape, while few studies are under the transportation field. The United States and China are the two leading countries conducting research on the field.

(3) Scholars have conducted extensive research in the following areas: influence of road construction on the surrounding areas, the influence of road network characteristics, and the influence of different road types and their cumulative effects. Researchers have conducted studies from different perspectives, including on urban areas focusing on construction land, on rural areas focusing on farming and forest lands, and on the overall region, which extends from urban areas into rural areas. The number of comprehensive research studies studying the whole region has been limited, particularly on urban agglomeration in economically developed regions. Also, long-term research studies have been insufficient.

(4) The influence mechanism of accessibility on land use and landscape pattern demonstrates the important role of accessibility. Accessibility is one of the most important factors affecting landscape pattern changes. Developments in transportation can improve accessibility levels and drive urban growth and also lead to landscape fragmentation. Therefore, landscape protection must be considered in transportation construction. Consequently, land urbanization can stimulate transportation development and increase the accessibility level.

5.2. Implications. With continued progress in transportation infrastructure construction, its impact on the land use and landscape pattern would persist. Reviewing the existing trends and popular research contents would help guide researchers to build on the current knowledge and identify areas that can be improved:

(1) In terms of discipline construction and theoretical research, international development trends in transportation geography and landscape ecology should be combined, particularly on the use of transportation geography-related theories. Further recommendations are as follows: (a) apply transportation geography-related theories; (b) construct quantitative identification and research methods measuring the influence of accessibility on land use and landscape pattern; and (c) review and confirm indicators showing the influence of accessibility on land use and landscape pattern, which would involve analyzing specific problems with quantitative indicators.

(2) By integrating GIS and RS technologies, large-scale and long-term studies become practicable and more achievable. Existing macroscale research studies have intrinsic limitations, particularly concerning the lack of discussion on the influence and differences of historical stages and region types, which have limited the analysis of interior mechanisms. The development of GIS and RS provides the possibility to obtain and process historical data, which are highly beneficial in overcoming existing research limitations.

(3) Research on the functional landscape of the city's interior should be implemented using big data. 
Due to limitations in data acquisition, gathering data involving residential, industrial, and commercial lands can be challenging. However, with developments in big data technology, understanding the features of different land types in urban areas can be accomplished by analyzing high-resolution remote sensing images, online maps, point of interest, and area of interest. While data collected in this manner may be less accurate than those collected by the government, they may have an important role in understanding the influence of accessibility on functional landscape patterns due to lower cost requirements and high time-effectiveness.

(4) It is imperative to learn how to apply related methods and models in transportation geography and landscape ecology. Applying methods and models of landscape ecology, such as the RV index, the optimal model, and the dynamic simulation model, has become very common. When studying accessibility, the Euclidean distance method and the gravity model method are often applied. In the future, more valuable research results would be obtained if the latest methods and models in transportation geography and landscape ecology are utilized.

\section{Data Availability}

The research data used to support the findings of this study are available from the corresponding author upon request.

\section{Conflicts of Interest}

The authors declare that there are no conflicts of interest regarding the publication of this paper.

\section{Acknowledgments}

The authors would like to acknowledge the research support received from the Humanity and Social Science Foundation of Ministry of Education of China (20YJCZH104 and 19YJCZH229) and thanks Yongwei Liu and Peng Yin for the foundation support.

\section{Supplementary Materials}

Supplementary materials include 286 published papers used for mapping knowledge domain analysis. Supplementary materials mainly include $N O$ (the serial number from 1 to 286), Title (the title of the papers), Author (the author of the papers), Journal (the publication journal of the papers), and Year (the publication time of the papers). (Supplementary Materials)

\section{References}

[1] C. Troll, "Luftbildplan und ökologische Bodenforschung. Ihr zweckmäßiger Einsatz für die wissenschaftliche Erforschung und praktische Erschließung wenig bekannter Länder,"
Zeitschrift der gesellschaft für erdkunde zu Berlin, vol. 7-8, pp. 241-298, 1939.

[2] M. G. Turner, R. H. Gardner, and R. V. O'neill, Landscape Ecology in Theory and Practice, Springer, Berlin, Germany, 2001.

[3] R. T. Forman, D. Sperling, J. A. Bissonette et al., Road Ecology: Science and Solutions, Island Press, Washington, DC, USA, 2003.

[4] B. Iuell, "Wildlife and traffic-a european handbook for identifying conflicts and designing solutions," The XXIInd PIARC World Road CongressWorld Road AssociationPIARC, World Road Association, Paris, France, 2003.

[5] J. A. G. Jaeger, T. Soukup, L. F. Madriñán, C. Schwick, and F. Kienast, Landscape Fragmentation in Europe, European Environment Agency, Copenhagen, Denmark, 2011.

[6] T. A. M. Kaphegyi, M. Dees, D. Zlatanova, C. Ueffing, A. Dutsov, and U. Kaphegyi, "Rapid assessment of linear transport infrastructure in relation to the impact on landscape continuity for large ranging mammals," Biodiversity and Conservation, vol. 22, no. 1, pp. 153-168, 2012.

[7] E. H. Girvetz, J. H. Thorne, A. M. Berry, and J. A. G. Jaeger, "Integration of landscape fragmentation analysis into regional planning: a statewide multi-scale case study from California, USA," Landscape and Urban Planning, vol. 86, no. 3-4, pp. 205-218, 2008.

[8] G. Bentrup, "Conservation buffers-design guidelines for buffers, corridors, and greenways," General Technical Report SRS-109, USDA Forest Service Southern Research Station, Asheville, NC, USA, 2008.

[9] S. C. Saunders, M. R. Mislivets, J. Chen, and D. T. Cleland, "Effects of roads on landscape structure within nested ecological units of the Northern Great Lakes Region, USA," Biological Conservation, vol. 103, no. 2, pp. 209-225, 2002.

[10] T. J. Hawbaker, V. C. Radeloff, M. K. Clayton, R. B. Hammer, and C. E. Gonzalez-Abraham, "Road development, housing growth, and landscape fragmentation in northern Wisconsin: 1937-1999," Ecological Applications, vol. 16, no. 3, pp. 1222-1237, 2006.

[11] G. Wu, F. Chen, X. Pan, M. Xu, and X. Zhu, "Using the visual intervention influence of pavement markings for rutting mitigation-part I: preliminary experiments and field tests," International Journal of Pavement Engineering, vol. 20, no. 6, pp. 734-746, 2019.

[12] F. Chen, M. Song, X. Ma, and X. Zhu, "Assess the impacts of different autonomous trucks' lateral control modes on asphalt pavement performance," Transportation Research Part C: Emerging Technologies, vol. 103, pp. 17-29, 2019.

[13] Y. Pu, F. Chen, P. Chen, and X. Pan, "Wind data collection and analysis of topographical features along a highway for traffic safety assessment based on mobile mapping technology," Transportation Research Record: Journal of the Transportation Research Board, vol. 2672, no. 42, pp. 292-301, 2018.

[14] D. Mukherjee and S. Mitra, "Impact of road infrastructure land use and traffic operational characteristics on pedestrian fatality risk: a case study of Kolkata, India," Transportation in Developing Economies, vol. 5, no. 2, 2019.

[15] S. Perveen, M. Kamruzzaman, and T. Yigitcanlar, "What to assess to model the transport impacts of urban growth? A Delphi approach to examine the space-time suitability of transport indicators," International Journal of Sustainable Transportation, vol. 13, no. 8, pp. 597-613, 2019.

[16] W. G. Hansen, "How accessibility shapes land use," Journal of the American Institute of Planners, vol. 25, no. 2, pp. 73-76, 1959. 
[17] C. Chen, "CiteSpace II: detecting and visualizing emerging trends and transient patterns in scientific literature," Journal of the American Society for Information Science and Technology, vol. 57, no. 3, pp. 359-377, 2006.

[18] R. Xiao, S. Su, J. Wang, Z. Zhang, D. Jiang, and J. Wu, "Local spatial modeling of paddy soil landscape patterns in response to urbanization across the urban agglomeration around Hangzhou Bay, China," Applied Geography, vol. 39, pp. 158-171, 2013.

[19] Y. Liu, Q. He, R. Tan, Y. Liu, and C. Yin, "Modeling different urban growth patterns based on the evolution of urban form: a case study from Huangpi, Central China," Applied Geography, vol. 66, pp. 109-118, 2016.

[20] A. Achmad, S. Hasyim, B. Dahlan, and D. N. Aulia, "Modeling of urban growth in tsunami-prone city using logistic regression: analysis of Banda Aceh, Indonesia," Applied Geography, vol. 62, pp. 237-246, 2015.

[21] C.-D. Kang, "The effects of spatial accessibility and centrality to land use on walking in Seoul, Korea," Cities, vol. 46, pp. 94-103, 2015.

[22] G. Tian and J. Wu, "Comparing urbanization patterns in Guangzhou of China and Phoenix of the USA: the influences of roads and rivers," Ecological Indicators, vol. 52, pp. 23-30, 2015.

[23] J. Chen, K.-T. Chang, D. Karacsonyi, and X. Zhang, "Comparing urban land expansion and its driving factors in Shenzhen and Dongguan, China," Habitat International, vol. 43, pp. 61-71, 2014.

[24] R. Tan, Y. Liu, Y. Liu, Q. He, L. Ming, and S. Tang, "Urban growth and its determinants across the Wuhan urban agglomeration, central China," Habitat International, vol. 44, pp. 268-281, 2014.

[25] M. Iacono, D. Levinson, and A. El-Geneidy, "Models of transportation and land use change: a guide to the territory," Journal of Planning Literature, vol. 22, no. 4, pp. 323-340, 2008.

[26] K.-W. Tsou, H.-T. Cheng, and F.-Y. Tseng, "Exploring the relationship between multilevel highway networks and local development patterns-a case study of Taiwan," Journal of Transport Geography, vol. 43, pp. 160-170, 2015.

[27] A. M. Hersperger and M. Bürgi, "Going beyond landscape change description: quantifying the importance of driving forces of landscape change in a Central Europe case study," Land Use Policy, vol. 26, no. 3, pp. 640-648, 2009.

[28] T.-Y. Zhong, X.-J. Huang, X.-Y. Zhang, and K. Wang, "Temporal and spatial variability of agricultural land loss in relation to policy and accessibility in a low hilly region of southeast China," Land Use Policy, vol. 28, no. 4, pp. 762769, 2011.

[29] W. Fu, S. Liu, S. D. Degloria, S. Dong, and R. Beazley, "Characterizing the "fragmentation-barrier" effect of road networks on landscape connectivity: a case study in Xishuangbanna, Southwest China," Landscape and Urban Planning, vol. 95, no. 3, pp. 122-129, 2010.

[30] M. Serrano, L. Sanz, J. Puig, and J. Pons, "Landscape fragmentation caused by the transport network in Navarra (Spain): two-scale analysis and landscape integration assessment," Landscape and Urban Planning, vol. 58, no. 2-4, pp. 113-123, 2002.

[31] X. Hu, Z. Wu, C. Wu et al., "Effects of road network on diversiform forest cover changes in the highest coverage region in China: an analysis of sampling strategies," Science of the Total Environment, vol. 565, pp. 28-39, 2016.
[32] S. Serneels and E. F. Lambin, "Proximate causes of land-use change in Narok District, Kenya: a spatial statistical model," Agriculture, Ecosystems \& Environment, vol. 85, no. 1-3, pp. 65-81, 2001.

[33] R. Patarasuk and M. W. Binford, "Longitudinal analysis of the road network development and land-cover change in Lop Buri province, Thailand, 1989-2006," Applied Geography, vol. 32, no. 2, pp. 228-239, 2012.

[34] J. Liang, Y. Liu, L. Ying, P. Li, Y. Xu, and Z. Shen, "Road impacts on spatial patterns of land use and landscape fragmentation in three parallel rivers region, Yunnan Province, China," Chinese Geographical Science, vol. 24, no. 1, pp. 15-27, 2014.

[35] F. Kong, H. Yin, N. Nakagoshi, and P. James, "Simulating urban growth processes incorporating a potential model with spatial metrics," Ecological Indicators, vol. 20, pp. 82-91, 2012.

[36] M. Karlson, U. Mörtberg, and B. Balfors, "Road ecology in environmental impact assessment," Environmental Impact Assessment Review, vol. 48, pp. 10-19, 2014.

[37] M. Aljoufie, M. Brussel, M. Zuidgeest, and M. van Maarseveen, "Urban growth and transport infrastructure interaction in Jeddah between 1980 and 2007," International Journal of Applied Earth Observation and Geoinformation, vol. 21, pp. 493-505, 2013.

[38] M. R. Crist, B. Wilmer, and G. H. Aplet, "Assessing the value of roadless areas in a conservation reserve strategy: biodiversity and landscape connectivity in the northern Rockies," Journal of Applied Ecology, vol. 42, no. 1, pp. 181-191, 2005.

[39] M. Antrop, "Landscape change and the urbanization process in Europe," Landscape and Urban Planning, vol. 67, no. 1-4, pp. 9-26, 2004.

[40] M. Antrop, "Why landscapes of the past are important for the future," Landscape and Urban Planning, vol. 70, no. 1-2, pp. 21-34, 2005.

[41] M. Luck and J. Wu, "A gradient analysis of urban landscape pattern: a case study from the Phoenix metropolitan region, Arizona, USA," Landscape Ecology, vol. 17, no. 4, pp. 327339, 2002.

[42] M. Bürgi, A. M. Hersperger, and N. Schneeberger, "Driving forces of landscape change-current and new directions," Landscape Ecology, vol. 19, no. 8, pp. 857-868, 2005.

[43] R. T. T. Forman, "Estimate of the area affected ecologically by the road system in the United States," Conservation Biology, vol. 14, no. 1, pp. 31-35, 2000.

[44] A. W. Coffin, "From roadkill to road ecology: a review of the ecological effects of roads," Journal of Transport Geography, vol. 15, no. 5, pp. 396-406, 2007.

[45] P. Serra, X. Pons, and D. Saurí, "Land-cover and land-use change in a Mediterranean landscape: a spatial analysis of driving forces integrating biophysical and human factors," Applied Geography, vol. 28, no. 3, pp. 189-209, 2008.

[46] R. T. T. Forman and R. D. Deblinger, "The Ecological roadeffect zone of a Massachusetts (USA) Suburban highway," Conservation Biology, vol. 14, no. 1, pp. 36-46, 2000.

[47] J. G. Wu and J. L. David, "A spatially explicit hierarchical approach to modeling complex ecological systems: theory and applications," Ecological Modelling, vol. 153, no. 1-2, pp. 7-26, 2002.

[48] X. Deng, J. Huang, S. Rozelle, and E. Uchida, "Growth, population and industrialization, and urban land expansion of China," Journal of Urban Economics, vol. 63, no. 1, pp. 96-115, 2008. 
[49] F.-F. Cheng, Y.-W. Huang, H.-C. Yu, and C.-S. Wu, "Mapping knowledge structure by keyword co-occurrence and social network analysis," Library Hi Tech, vol. 36, no. 4, pp. 636-650, 2018.

[50] F. Wu and A. G.-O. Yeh, "Changing spatial distribution and determinants of land development in Chinese cities in the transition from a centrally planned economy to a socialist market economy: a case study of Guangzhou," Urban Studies, vol. 34, no. 11, pp. 1851-1879, 1997.

[51] J. Luo and Y. H. D. Wei, "Modeling spatial variations of urban growth patterns in Chinese cities: The case of Nanjing," Landscape and Urban Planning, vol. 91, no. 2, pp. 51-64, 2009.

[52] F. Xie and D. Levinson, "How streetcars shaped suburbanization: a Granger causality analysis of land use and transit in the Twin Cities," Journal of Economic Geography, vol. 10, no. 3, pp. 453-470, 2010.

[53] X. Deng, J. Gibson, and S. Jia, "Does Expressway Consume More Land of the Agricultural Production Base of Shandong Province?" Computational Economics, vol. 52, no. 4, pp. 1293-1316, 2018.

[54] K. Müller, C. Steinmeier, and M. Küchler, "Urban growth along motorways in Switzerland," Landscape and Urban Planning, vol. 98, no. 1, pp. 3-12, 2010.

[55] T. M. Conway, "Current and future patterns of land-use change in the coastal zone of New Jersey," Environment and Planning B: Planning and Design, vol. 32, no. 6, pp. 877-893, 2016.

[56] C. Mothorpe, A. Hanson, and K. Schnier, "The impact of interstate highways on land use conversion," The Annals of Regional Science, vol. 51, no. 3, pp. 833-870, 2013.

[57] M. J. Iacono and D. M. Levinson, "Predicting land use change," Transportation Research Record: Journal of the Transportation Research Board, vol. 2119, no. 1, pp. 130-136, 2009.

[58] R. T. T. Forman and L. E. Alexander, "Roads and their major ecological effects," Annual Review of Ecology and Systematics, vol. 29, no. 1, pp. 207-231, 1998.

[59] R. Reijnen, R. Foppen, and G. Veenbaas, "Disturbance by traffic of breeding birds: evaluation of the effect and considerations in planning and managing road corridors," Biodiversity and Conservation, vol. 6, no. 4, pp. 567-581, 1997.

[60] C.-F. Wu, Y.-P. Lin, L.-C. Chiang, and T. Huang, "Assessing highway's impacts on landscape patterns and ecosystem services: A case study in Puli Township, Taiwan," Landscape and Urban Planning, vol. 128, pp. 60-71, 2014.

[61] Z. Hu and C. P. Lo, "Modeling urban growth in Atlanta using logistic regression," Computers, Environment and Urban Systems, vol. 31, no. 6, pp. 667-688, 2007.

[62] T. J. Hawbaker, V. C. Radeloff, R. B. Hammer, and M. K. Clayton, "Road density and landscape pattern in relation to housing density, and ownership, land cover, and soils," Landscape Ecology, vol. 20, no. 5, pp. 609-625, 2005.

[63] T. Luo, T. Zhang, Z. Wang, and Y. Gan, "Driving forces of landscape fragmentation due to urban transportation networks: lessons from Fujian, China," Journal of Urban Planning and Development, vol. 142, no. 2, 2016.

[64] X. Cai, Z. Wu, and J. Cheng, "Using kernel density estimation to assess the spatial pattern of road density and its impact on landscape fragmentation," International Journal of Geographical Information Science, vol. 27, no. 2, pp. 222-230, 2013.
[65] S. L. Liu and Y. H. Dong, "Characterizing the hierarchy of road network and its landscape effect with graph theory," Lecture Notes in Computer Science, vol. 8, p. 152, 2008.

[66] F. Pauwels and H. Gulinck, "Changing minor rural road networks in relation to landscape sustainability and farming practices in West Europe," Agriculture, Ecosystems \& Environment, vol. 77, no. 1-2, pp. 95-99, 2000.

[67] S. Nogués and A. Cabarga-Varona, "Modelling land use changes for landscape connectivity: The role of plantation forestry and highways," Journal for Nature Conservation, vol. 22, no. 6, pp. 504-515, 2014.

[68] S. Liu, L. Deng, Q. Zhao, S. D. DeGloria, and S. Dong, "Effects of road network on vegetation pattern in Xishuangbanna, Yunnan Province, Southwest China," Transportation Research Part D: Transport and Environment, vol. 16, no. 8, pp. 591-594, 2011.

[69] S. Su, R. Xiao, D. Li, and Y. N. Hu, "Impacts of transportation routes on landscape diversity: a comparison of different route types and their combined effects," Environmental Management, vol. 53, no. 3, pp. 636-647, 2014.

[70] T. Li, F. Shilling, J. Thorne et al., "Fragmentation of China's landscape by roads and urban areas," Landscape Ecology, vol. 25, no. 6, pp. 839-853, 2010.

[71] I. Pătru-Stupariu, M.-S. Stupariu, C. A. Tudor et al., "Landscape fragmentation in Romania's southern Carpathians: testing a European assessment with local data," Landscape and Urban Planning, vol. 143, pp. 1-8, 2015.

[72] B. Bhatta, Analysis of Urban Growth and Sprawl from Remote Sensing Data, Springer, Berlin, Germany, 2010.

[73] I. E. Ayazli, F. Kilic, S. Lauf, H. Demir, and B. Kleinschmit, "Simulating urban growth driven by transportation networks: A case study of the Istanbul third bridge," Land Use Policy, vol. 49, pp. 332-340, 2015.

[74] M. Aljoufie, M. Zuidgeest, M. Brussel, and M. van Maarseveen, "Spatial-temporal analysis of urban growth and transportation in Jeddah City, Saudi Arabia," Cities, vol. 31, pp. 57-68, 2013.

[75] Z. Wang and C. Lu, "Urban land expansion and its driving factors of mountain cities in China during 1990-2015," Journal of Geographical Sciences, vol. 28, no. 8, pp. 1152 1166, 2018.

[76] X. Li, W. Zhou, and Z. Ouyang, "Forty years of urban expansion in Beijing: What is the relative importance of physical, socioeconomic, and neighborhood factors?" Applied Geography, vol. 38, pp. 1-10, 2013.

[77] Z. Zhang, S. Su, R. Xiao, D. Jiang, and J. Wu, "Identifying determinants of urban growth from a multi-scale perspective: A case study of the urban agglomeration around Hangzhou Bay, China," Applied Geography, vol. 45, pp. 193-202, 2013.

[78] H. Ju, Z. Zhang, L. Zuo et al., "Driving forces and their interactions of built-up land expansion based on the geographical detector-a case study of Beijing, China," International Journal of Geographical Information Science, vol. 30, no. 11, pp. 2188-2207, 2016.

[79] T. Lin, C. Sun, X. Li et al., "Spatial pattern of urban functional landscapes along an urban-rural gradient: A case study in Xiamen City, China," International Journal of Applied Earth Observation and Geoinformation, vol. 46, pp. 22-30, 2016.

[80] M. Eker and H. O. Coban, "Impact of road network on the structure of a multifunctional forest landscape unit in southern Turkey," Journal of Environmental Biology, vol. 31, no. 1-2, pp. 157-168, 2010.

[81] X. Zhao, J. Pu, X. Wang, J. Chen, L. Yang, and Z. Gu, "Landuse spatio-temporal change and its driving factors in an 
artificial forest area in Southwest China," Sustainability, vol. 10, no. 11, p. 4066, 2018.

[82] K. McGarigal, W. H. Romme, M. Crist, and E. Roworth, "Cumulative effects of roads and logging on landscape structure in the San Juan Mountains, Colorado (USA)," Landscape Ecology, vol. 16, no. 4, pp. 327-349, 2001.

[83] S. R. Freitas, T. J. Hawbaker, and J. P. Metzger, "Effects of roads, topography, and land use on forest cover dynamics in the Brazilian Atlantic Forest," Forest Ecology and Management, vol. 259, no. 3, pp. 410-417, 2010.

[84] P. H. Verburg, K. P. Overmars, and N. Witte, “Accessibility and land-use patterns at the forest fringe in the northeastern part of the Philippines," The Geographical Journal, vol. 170, no. 3, pp. $238-255,2004$.

[85] S.-L. Shaw, "Transportation and Land Use," International Encyclopedia of Human Geography, vol. 21, no. 3, pp. 470475, 2009.

[86] J.-C. Castella, P. H. Manh, S. P. Kam, L. Villano, and N. R. Tronche, "Analysis of village accessibility and its impact on land use dynamics in a mountainous province of northern Vietnam," Applied Geography, vol. 25, no. 4, pp. 308-326, 2005.

[87] H. Nagendra, J. Southworth, and C. Tucker, "Accessibility as a determinant of landscape transformation in western Honduras: linking pattern and process," Landscape Ecology, vol. 18, no. 2, pp. 141-158, 2003.

[88] C. N. Berg, B. Blankespoor, and H. Selod, "Roads and rural development in Sub-Saharan Africa," The Journal of Development Studies, vol. 54, no. 5, pp. 856-874, 2018.

[89] M. J. McDonnell and S. T. A. Pickett, "Ecosystem structure and function along urban-rural gradients: an unexploited opportunity for ecology," Ecology, vol. 71, no. 4, pp. 1232$1237,1990$.

[90] Y.-C. Weng, "Spatiotemporal changes of landscape pattern in response to urbanization," Landscape and Urban Planning, vol. 81, no. 4, pp. 341-353, 2007.

[91] R. Reimets, E. Uuemaa, T. Oja, E. Sisas, and Ü. Mander, "Urbanisation-related landscape change in space and time along spatial gradients near roads: a case study from Estonia," Landscape Research, vol. 40, no. 2, pp. 192-207, 2015.

[92] M. Zhu, J. Xu, N. Jiang, J. Li, and Y. Fan, "Impacts of road corridors on urban landscape pattern: a gradient analysis with changing grain size in Shanghai, China," Landscape Ecology, vol. 21, no. 5, pp. 723-734, 2006.

[93] R. Zhang, L. Pu, and M. Zhu, "Impacts of transportation arteries on land use patterns in urban-rural fringe: A comparative gradient analysis of Qixia District, Nanjing City, China," Chinese Geographical Science, vol. 23, no. 3, pp. 378-388, 2012.

[94] K. Brinkmann, J. Schumacher, A. Dittrich, I. Kadaore, and A. Buerkert, "Analysis of landscape transformation processes in and around four West African cities over the last 50 years," Landscape and Urban Planning, vol. 105, no. 1-2, pp. 94-105, 2012.

[95] R. D. Watts, R. W. Compton, J. H. McCammon et al., "Roadless space of the conterminous United States," Science, vol. 316, no. 5825, pp. 736-738, 2007.

[96] W. Fu, S. Liu, and S. Dong, "Landscape pattern changes under the disturbance of road networks," Procedia Environmental Sciences, vol. 2, pp. 859-867, 2010.

[97] D. Kasraian, K. Maat, D. Stead, and B. van Wee, "Long-term impacts of transport infrastructure networks on land-use change: an international review of empirical studies," Transport Reviews, vol. 36, no. 6, pp. 772-792, 2016.
[98] M. Wegener and F. Fuerst, "Land-use transport interaction: state of the art," in Deliverable D2a of the Project TRANSLAND (Integration of Transport and Land Use Planning), University of Dortmund, Dortmund, Germany, 1999.

[99] L. Bertolini, "Integrating mobility and urban development agendas: a Manifesto," disP-The Planning Review, vol. 48, no. 1, pp. 16-26, 2012.

[100] G. Giuliano, "Land use impacts of transportation investments: Highway and transit," pp. 237-273, Guilford Publications, New York, NY, USA, 2004. 